\title{
RESEARCH AND TECHNOLOGICAL INNOVATION FOR THE KNOWLEDGE, CONSERVATION AND VALORIZATION OF CULTURAL HERITAGE IN SICILY
}

\author{
Alessio Cardaci ${ }^{1}$, Antonella Versaci \\ ${ }^{1}$ Department of Engineering and S.A., University of Bergamo, Bergamo, Italy - alessio.cardaci@unibg.it \\ ${ }^{2}$ Faculty of Engineering and Architecture, University of Enna "Kore”, Enna, Italy - antonella.versaci@unikore.it
}

\author{
Commission II, WG II/8
}

KEY WORDS: digital innovation, 3D modelling, reverse engineering, cultural heritage, Sicily, Sebastiano Tusa.

\begin{abstract}
In our time, new technologies are progressively more and more approaching the cultural heritage's world. The opportunity to obtain - quickly and in a non-invasive way - virtual models of ancient sites, monuments and objects, using data taken by photo-modelling, digital photogrammetry or laser scanning techniques, offers new possibilities for their proper documentation, monitoring, physical conservation, restoration, archiving and valorization. Moreover, reverse engineering techniques allow a deeper understanding of architectural artefacts and collections by increasing their communication, display and interpretation. By showing a number of experiences related to the rich and famous archaeological heritage of Sicily Island, this paper intends to highlight how the use of new digital equipment and methodologies can be of great benefit for its safeguarding, representation, promotion and enjoyment.
\end{abstract}

\section{INTRODUCTION}

The multidisciplinary interchange between research fields involved in cultural heritage's knowledge, protection and communication underlies the technical and methodological advancement today reached. The use of 3D modelling and the application of reverse engineering and rapid prototyping, borrowed from the world of industrial design, together with the new techniques of computer vision and computer graphics developed by the information technology sector, is increasingly becoming a valuable support to the project of awareness and analysis aimed at the study and safeguarding of cultural heritage.

The ability to quickly obtain digital models of sites, historic buildings and ancient objects, using data acquired through recent applications of image-based 3D modelling and traditional photogrammetry techniques and/or laser scanning, offers new possibilities for their proper documentation, analysis, conservation and enhancement. In addition, the opportunity to make replica of large and small-scale objects through 3D printers and other additive manufacturing systems or numerical control machines, combining them with virtual models and drawings, can ensure their deeper understanding. It also allows communicating them in a more intuitive and natural style, so improving knowledge, monitoring, educational resource and museum exhibit aspects (Cardaci \& Versaci, 2018).

The acquisition is the first step in the data processing to which follows the 3D modelling for the creation of both virtual textured and navigable artefacts, and physical replicas: models from reality able to provide a more convincing description of the object, based on accurate metric data and also providing materials and degradation phenomena's information. The new options are not merely related to the use of maquettes (ancient practice, but expensive in terms of time and effort), but to their rapid and multiple production. The 3D modelling software transfor$\mathrm{ms}$ the cloud's fragmentary data from a discrete (or continuous) surface to a polygonal model allowing editing processes both for the correction of possible errors and for the reconstruction of the eventual holes or gaps in the surface to be printed. The polygonal model, unlike the point cloud, optimizable by the re- duction of the total number of triangles to a predetermined value and the high-resolution texture mapping by photographic images, can be easily shared by the web and then used to realize copies everywhere. Finally, the contribution provided by the creation of videos and animations in digital and multi-media productions, ensures the communication of contents and the models navigation, in an interactive and immediate way, to a wider audience. In this context, it is located a large part of the research that the Laboratory of Diagnostics and Restoration of Architectural and Cultural Heritage of Kore University of Enna with the intellectual and instrumental support of Lab SABE - Survey \& Analysis of Building and Environment of the University of Bergamo, for several years have been conducting in the field of new technologies for cultural heritage. This work aims to show some of the most significant activities carried out, focusing in particular on the rich and famous Sicilian archaeological heritage.

\section{ARCHAEOLOGICAL HERITAGE IN SICILY}

Sicily, a land rich in history located at the heart of the Mediterranean Sea, is a place that still allows a unique journey back in time. Numerous are indeed the testimonies - many of which still well preserved - of its ancient past and of the people who lived there: from the first sedentary tribes of the Sicels, Sicans, Elymians to the Phoenicians, Greeks, Romans, Byzantines, Arabs and Normans.

The territory's diversity, the mild climate, the vastness of its plains and mountains, the strategic geographic position that ensured it the role of bridge between Europe and Africa, as well as the close relationship with the Attic peninsula, are the reasons of the huge archaeological heritage that documents the millenary origins of the island. A vast cultural inheritance consisting of necropolis, ruins of the ancient cities, visible pieces of rock paintings, traces related to the sea and the art of navigation and returned through the remains of boats and the content of their cargos, signs of a past crystallized on stone carvings, decorations on ceramics and numerous sculptures and architectural works of art.

In Sicily, there are currently 14 archaeological parks, including 
22 galleries and places for permanent exhibitions, 17 archaeological museums, 78 archaeological sites and monuments as well as seven sites inscribed on the UNESCO World Heritage Site, including 3 archaeological ones. These data highlight the size of a heritage whose complexity can largely profit from new technologies applied to its management and improvement (Fig. 1).

New technologies, in fact, may today allow the implementation of a project of knowledge aimed at the conservation and enhancement of this great heritage of arts and traditions, based on the accuracy of historical and documentary sources, implemented by means of accurate investigations, disclosed and made available to a wide audience thanks to the potentialities offered by the web (El-Hakim et. al, 2008; Russo et al., 2011; Guidi et al., 2014). All that is hosted on the Internet can quickly be communicated through drawings and images and rapidly understood through the exploration of 3D models - even by low-cost computers -, so obtaining an immersive and interactive approach to visiting real vely concerning:

- the Cozzo San Giuseppe Necropolis in the Realmese district of Calascibetta (Enna). An important archaeological site located in a deep valley where, on the side facing south, are still visible 288 burial caves whose use originated in the historic era (mid- $9^{\text {th }}$ century BC - first half of the $7^{\text {th }}$ century BC) to perform interment functions and which were also used during the archaic age (mid$7^{\text {th }}$ century - second quarter of the $6^{\text {th }}$ century BC). Over the centuries, the Necropolis has undergone changes that led to the reuse with housing functions of some of the burials and, therefore, to their modification in response to the new requirements (Bernabò Brea, 1882). The work undertaken concerned the site in all its complexity - the underground architecture and the archaeological remains found in burials - and was conducted through advanced techniques of image-based 3D modelling, laser scanning systems at scales and different resolutions and rapid prototyping. The results were included in a larger research aimed at creating a mul-
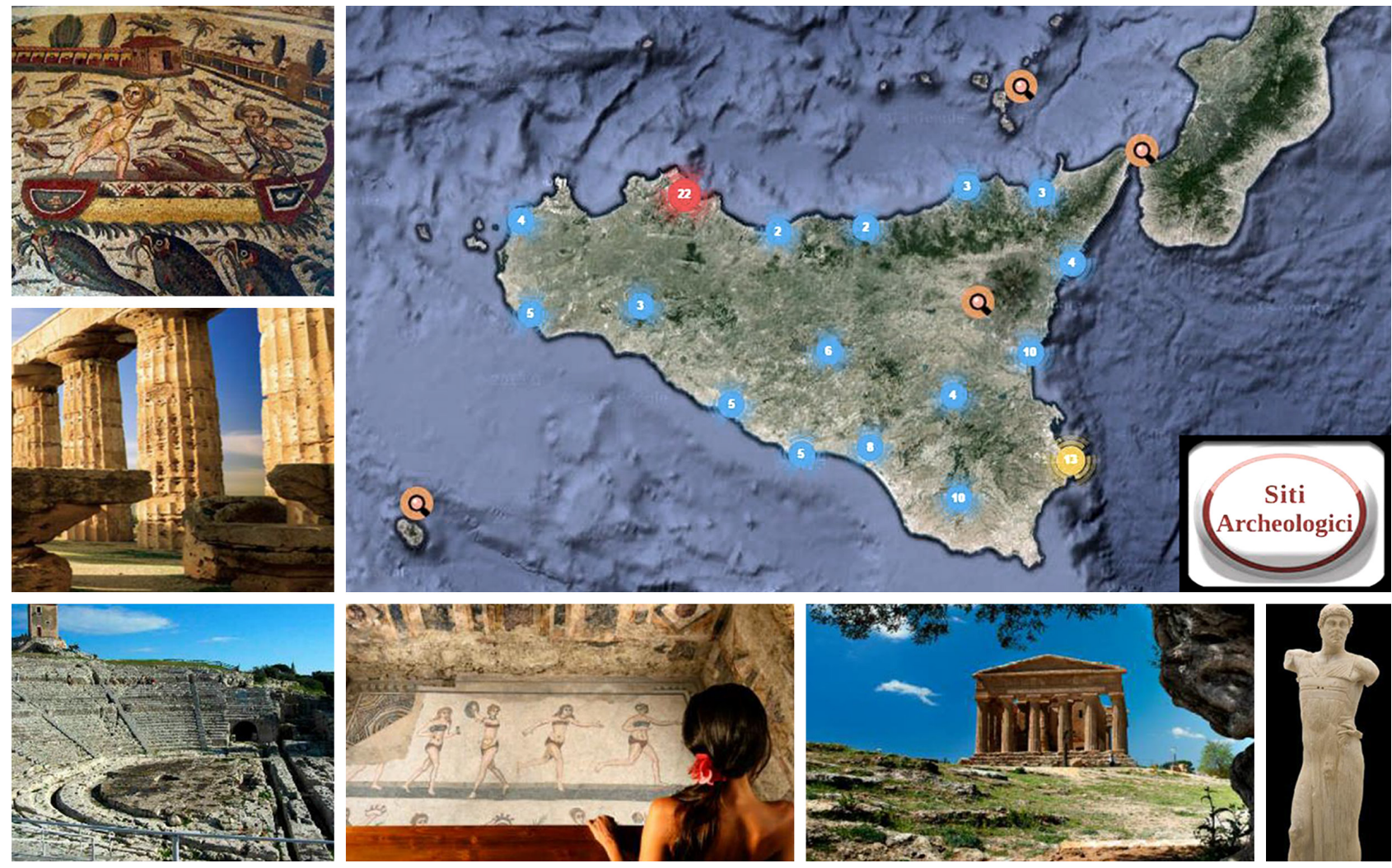

Figure 1 . Sicily and its rich archaeological heritage.

places, also physically distant. An opportunity to date, unfortunately, only partially implemented because it is linked to an archaic view of the network as a 'static' structure like a big library where just to find information.

3D cataloguing of monuments, virtualization of the collections and, in general, any chance offered by the Information and Communication Technology (ICT) and the techniques for the development of web virtual museums could allow the use of this intellectual heritage of Sicily dislocated and fragmented across a broad territory (Yehuda et al. 2007; Luigini et al., 2019). Online platforms, if properly employed, are suitable for the dissemination and communication of a very broad legacy and, as a result, for many aspects little known and not adequately used.

With this awareness, a number of initiatives were brought forward by the authors of this paper. Between them there are some case studies of particular relevance, such as those respecti- timedia platform: a sort of virtual archive for both the archaeological site and the objects, today scattered between two museums: the Regional Archaeological Museum "Paolo Orsi" in Syracuse and the Regional Interdisciplinary Museum of Enna;

- the Acroliths from the ancient Greek site of Morgantina. Acroliths were statues generally made with wooden trunks and marble heads; dating to $6^{\text {th }}$ century $\mathrm{BC}$, this is one of the oldest in the Western world. The eight fragments comprising two heads, hands and feet, carved in marble from the island of Thasos, belong to two life-size statues of slightly more than true, depicting two goddesses seated, side by side, which are identifiable as Demeter and Kore (Marconi, 2008).

Looted in ca. 1979 and subsequently sold in London to a New York collector, who in December 2002 agreed to give them to the University of Virginia, they returned close to home recently and are on display in Aidone, a town of about 6,000 inhabitants near 
Enna. Specific examples of the Sicilian identity and unquestioned values of Mediterranean civilization, the Acroliths were chosen as symbolic elements of the Piazzetta, the pavilion of Sicily at the Expo 2015 in Milan. Therefore, they were first subject to careful conservation work carried out by the Centro regionale per la Progettazione e il Restauro (Regional Centre for Planning and Restoration) of the Sicilian Region. As part of the preliminary diagnostic investigation, a campaign of non-contact 3D measurement was carried out. It allowed to obtain the exact geometry of the pieces by means of virtual models showing the presence of abrasions, scratches or other discontinuities of surfaces, in order to better orient - together with the results of other analysis and diagnostic investigations - restoration operations (Fig. 2);

- the artefacts discovered during the recent archaeological research conducted by the governmental underwater cultural heritage authority - the Soprintendenza del Mare (Superintendence of the Sea) - in the deep waters of the Egadi islands off north-west Sicily and probably, dating back to the naval battle of March 10, 241 BC between the Roman and Carthaginian fleets (Fig. 3). In particular, activities concerned a rostrum and five of the seven bronze helmets of Italic montefortino typology (Sanz, 2007); one of them, not yet restored, had the characteristics concretions formed over thousands of years living in the depths of the Mare Nostrum. The operations were carried out through high-definition 3D survey techniques and reverse engineering to create - not only virtual but also - physical copies made by three-dimensional printers and $\mathrm{CNC}$ machines; for the online exploitation of data and textured polygon models of the objects, a new tool for creating web presentations and interactive multimedia was used. To undertake these activities were then employed - in an integrated manner - different new techniques and equipment and put in place a number of procedures that deserve to be further specified.

\section{ACQUISITION, PROCESSING AND COMMUNICA- TION OF THE ARCHAEOLOGICAL HERITAGE}

The instruments and methods used for the digitisation of the architecture and archaeological findings are manifold and need to be, in general, selected and optimized based on both the characteristics of the cultural property to be studied and the aims pursued. Even if digital models are in our time, largely present and more and more developed, their generation still needs considerable effort and the choice of the most appropriate 3D modelling technique is an essential step to accomplish as well as to foresee appropriate modalities of integration. The case studies here described have been imprinted on these criteria, in order to obtain results comprehensive and representative of a correct modus operandi. Despite the diversity of each specific context it is, however, possible to see in every situation a common operational practice based on three main stages: acquisition, processing and export. The first phase - the acquisition - is that of the capture of the reality that operates the conversion - in the form of digital information - of the geometry, material and chromatic characteristics of the artefacts. The raw data - often redundant and unnecessary because in part detected by automated and non-selective procedures - are not able to describe the object and highlight its main features. A 'treatment' process is needed in order to sort, organize and made them consultable and accessible, through specific graphic interfaces. The 3D digital model thus produced still has to be further processed as a function of its final use; this last phase is commonly referred to as the 'export'. In it, the digital model undergoes a series of transformations and adaptations in order to be integrated within a web platform, or for the realization of physical copies at different scale, or even for use in rendering applications for the production of videos or short films.
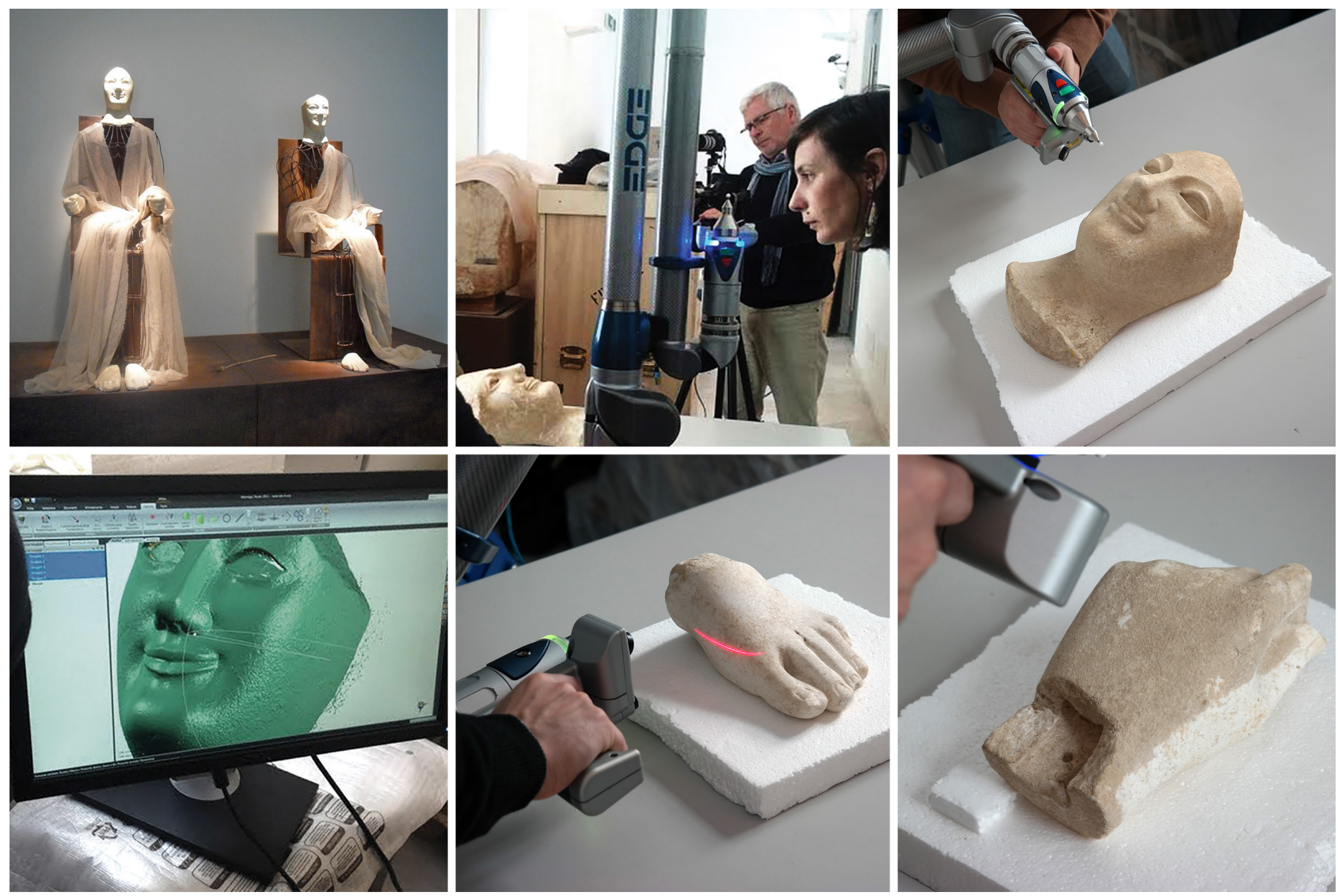

Figure 2. 3D survey activities related to the Acroliths from the ancient Greek site of Morgantina. 

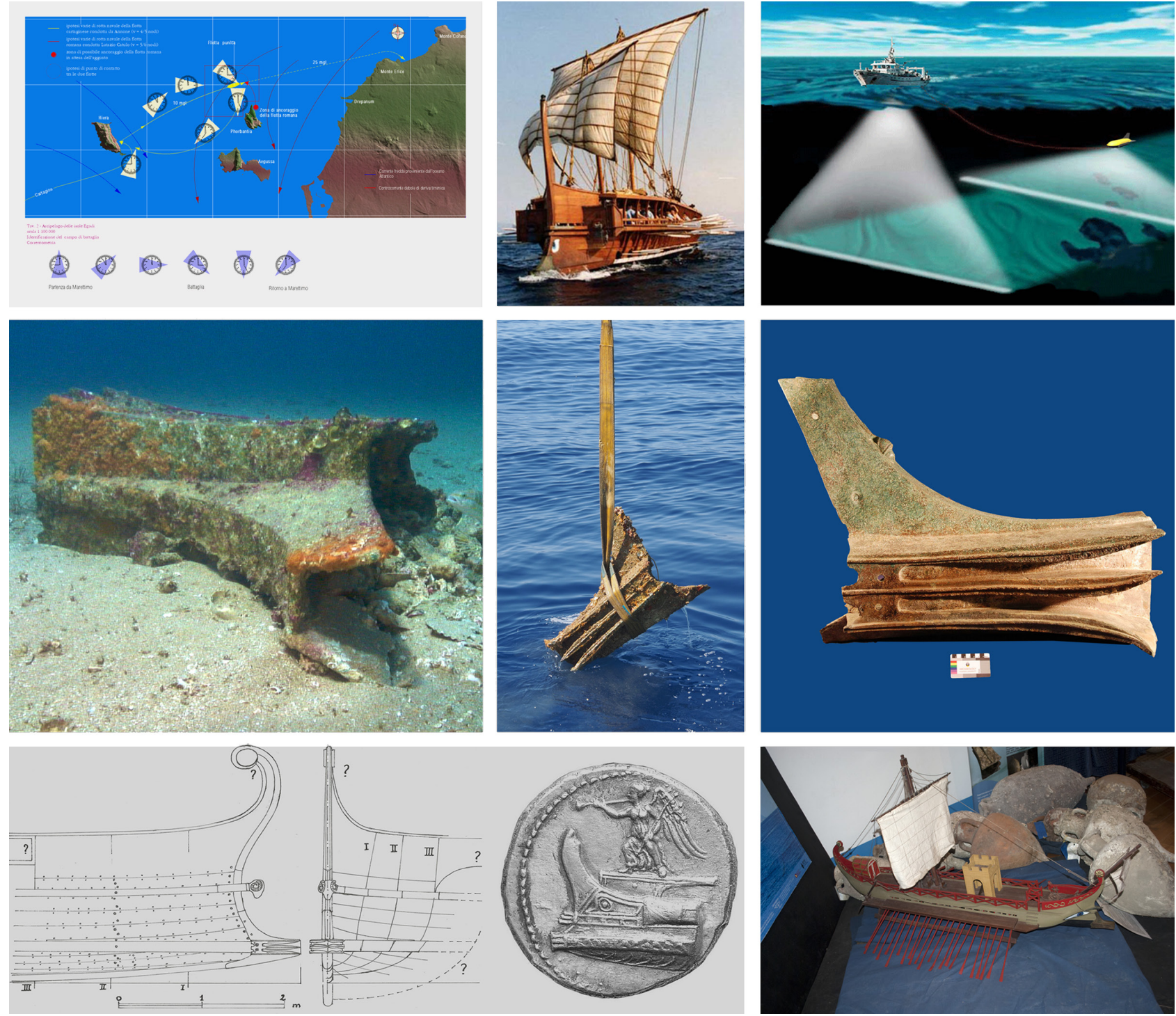

Figure 3. Archaeological research conducted by the Soprintendenza del Mare in the deep waters of the Egadi islands.

In the case of the Cozzo San Giuseppe Necropolis, acquisition phases were conducted simultaneously with 3D laser scanning and photogrammetry equipment. Both non-contact methods based on light waves, the two techniques are complementary and the creation of several models based on the use of information acquired by active sensors (laser scanner) and passive sensors (digital camera) has granted a greater flexibility in the data processing and good integration opportunities. In fact, the images captured by professional reflex cameras and lenses of good quality, with the necessary precautions aimed at obtaining a technically correct picture in focusing and exposure, have allowed the creation of virtual models (not metrically accurate but of high chromatic quality). Moreover, they have also been employed for the texturing of digital artefacts created from the data acquired with laser scanning techniques (very accurate in geometric precision, but deficient, when not missing, in chromatic data). Actually, some laser systems directly acquire colour information for each pixel while others, such has that used for this experience have a colour camera attached to the instrument, in a known configuration, so that the acquired texture is always registered with the geometry. However, this approach may not provide the best results since the ideal conditions for taking the images may not coincide with those for scanning. To generate a first general model related to the whole necropolis, located on a slope rather wide, stretching for more than 300 meters, special attention was paid in defining the paths to follow for acquisitions cameras.

To obtain images of the entire extent of the site, four paths were so created. The first two were placed in the opposite side of the valley, along two paths - almost parallel to each other - respectively upstream and downstream of the rise, the third ran along the path downstream, near the necropolis, while the fourth was identified in a small alleyway to the east of the necropolis near the nearby quarry. The photographic campaign, conducted with a full frame camera whose large sensor has a reduced noise, required the use of a sturdy tripod for the shooting aperture priority mode, with values chosen between $\mathrm{f} 16$ and $\mathrm{f} 22$ for a wide depth of field, and a very long time of shutter opening; about 300 photographs were taken by using several wide-angle lenses.

Developed from data RAW TIF files, pictures were processed using the Agisoft PhotoScan: a software based on the 'structure from motion' principle (SfM). Born from the convergence of different disciplines - on one hand the Computer Vision, which aims the automatic generation of 3D models, and on the other, the photogrammetry that has as objective the measurable documentation of the object - this technique enables to get an automatic $3 \mathrm{D}$ reproduction from pictures of objects, archaeological sites 

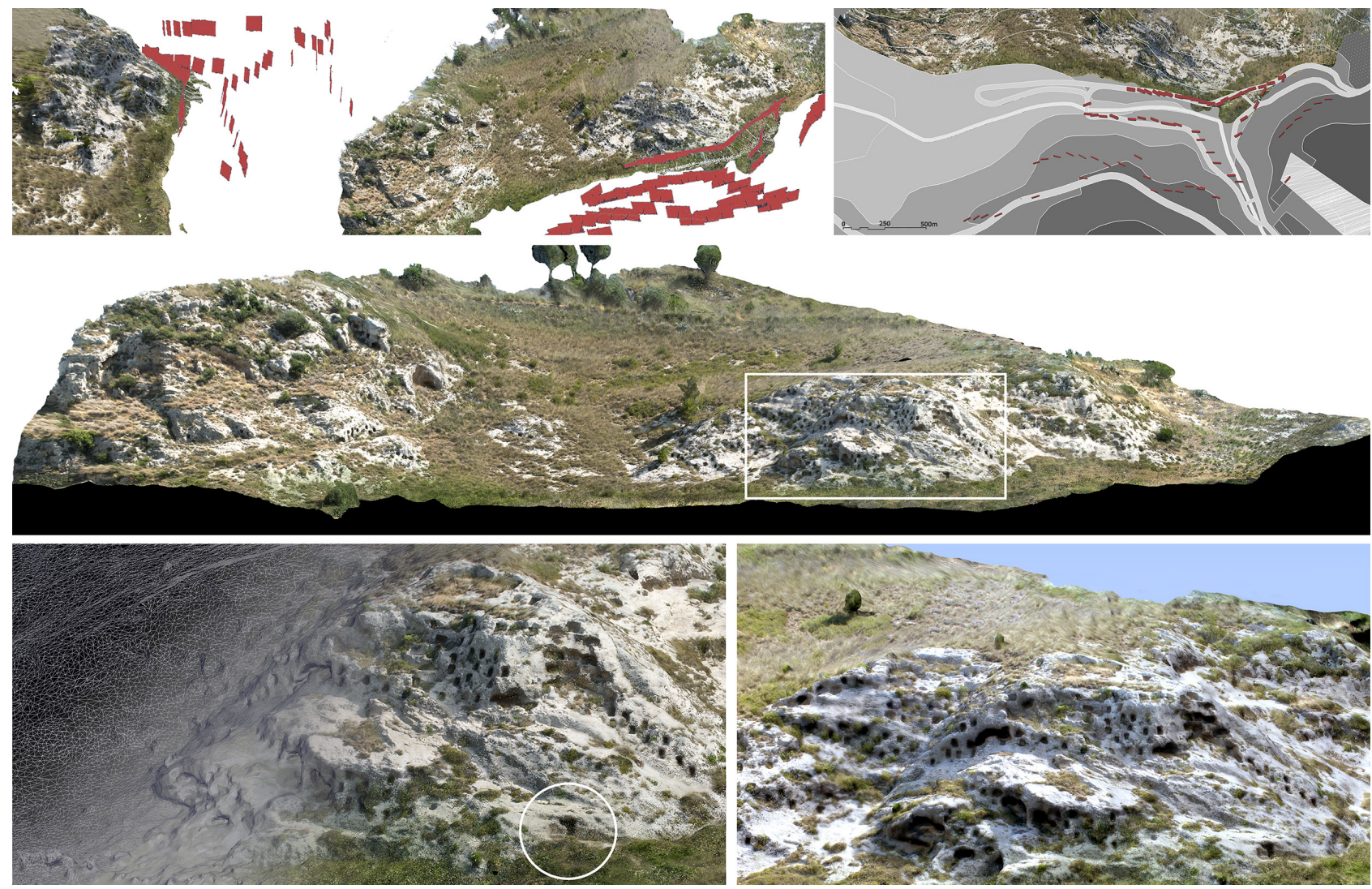

Figure 4. Activities related to the production of virtual models of the Cozzo San Giuseppe Necropolis by 3D image-based modelling.

and whole urban districts with a minimal economic investment (Fig. 4). The photogrammetric technique requires that each frame is properly oriented and placed in a single system of reference, and this is conceivable if, for each pair of images taken from two different points of view, there are at least five homologous points. By identifying, in fact, in both photographs, common and unequivocally recognizable points, it is possible to determine the geometry of the socket (the position and the orientation of the camera at the click) to then calculate, through the principle of collinearity, the spatial coordinates of collimated points.

The collimation of the homologous points, long and complex operation with traditional systems, is instead automatic thanks to image-based 3D modelling software such as that were used, which allows from a high number of photographs - even uncalibrated but with a high overlap - the recognition and the automatic extraction of matching features and the return of a complete and geo-referenced point cloud. The subsequent conversion into a model of about 300,000 polygons, on which has been possible the high-resolution photographic mapping, has resulted in a loyal and highly realistic model of the archaeological site.

The 3D terrestrial laser scanning technique has, however, been used for the acquisition of part of the graves, including their interior space. In particular, a direct distance measurement device based on the 'phase shift' (PS) functioning - the Faro Focus 3D - has been chosen as considered the most suitable instrument for medium range applications (interiors or small/medium architectural structures including ipogea as in the specific case) and archaeological sites. Its speed, in the range of 1 million points per second and its easy handling due to the small size and reduced weight, allows it to be successfully employed in complex structures where several scanner positioning are needed, without compromising a high level of geometric accuracy $( \pm 2 \mathrm{~mm})$.

Finally, a triangulation tool - the Faro Arm Edge - integrated with a laser probe mounted at the end of a measuring arm with seven freedom degrees (this technology is defined handheld 3D scanner), was employed for the detection of funerary tombs, as well as for the Morgantina acroliths (Fig. 5), the helmets and the rostrum from the Egadi's Battle. Thanks to the characteristics of this instrumentation, the operator was able to manoeuvre the tool manually, without moving the object in every measurement, thus obtaining a very high accuracy (a few tens of microns).

In all processes, these techniques have provided, as instrumental output, the point clouds even if 'raw' and 'partial' ones. It has therefore been necessary to remove the unwanted elements, mechanically acquired by the instrument, not belonging to the object and to filter the background noise of the data to improve their legibility.

Finally, it has been necessary to provide for the alignment of partial scans, through the operations of roto-translation on a scan chosen as a reference, through the identification of at least three points in common to at least two scans.

The largest part of the process is, however, represented by the 3D modelling, realized by the Geomagic Studio software, which first act is the transformation of the point cloud into a discrete - or continue - surface through the generation of meshes, fragmented surfaces consisting of triangular polygons whose vertices are all the points making up the cloud. The model obtained is a polygonal solid which will be subjected to further automatic procedures of cleaning and, therefore, to a subsequent aging in the recording - through an 'iterative closest point' algorithm (ICP) that aligns each range scan by reason of the shape of its surfaces and not only on the basis of the targets - and to the union of the mesh into a single object.

A good practice for obtaining polygonal models faithful and, at the same time, optimized for an easy handling, is to use decimation algorithms that preserve the curvature values of the surfaces. 

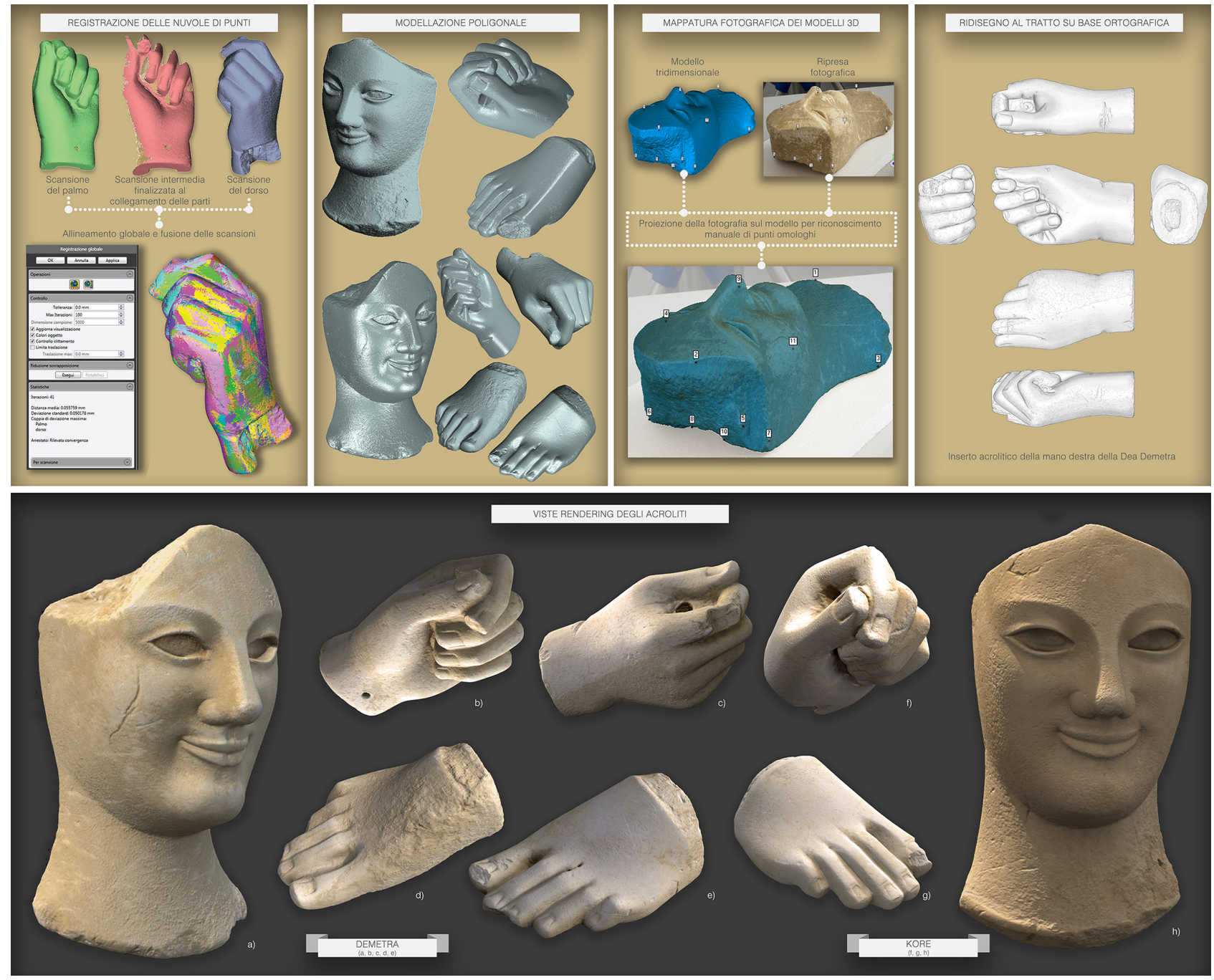

Figure 5. 3D models of Morgantina's Acroliths: acquisition procedure by handheld 3D scanner technology and results.

Taking care to set the point cancellation only where the surface has a greater regularity and can then be approximated to regular geometries, the mesh will be 'lighter' only in the parts with values of low or zero curvature (smooth parts or flat) and very dense in parties with considerable curvature values (parts with accented details). The polygonal model, now united, passes a final editing stage for the correction of errors that occurred during the merge process, closing the gaps and discontinuities; it is then optimized by reducing the total number of triangles to a specified value, mapped by textures obtained from separate high-resolution colour digital cameras and subjected to the final rendering. The activity related to the necropolis of Realmese and those concerning the underwater findings included making copies of objects respectively in scale $1: 1$ and $1: 5$ by means of the $3 \mathrm{D}$ printer Objet24 (Fig. 6). Its functioning principle, based on additive processes - that is, the piece is built with the superposition of ultra-thin layers of polymeric liquid compounds -, has allowed the establishment of faithful resin models with an accuracy of only 28 microns. A further replication of the rostrum has been realised in scale 1: 1, with the Isel FlatCom M40 - a CNC machine that works by subtraction of material -, using composite panel built with an extruded polystyrene core with density $30 \mathrm{Kg} / \mathrm{mq}$. The large size of the object and its complex morphology have imposed a processing for individual parts, with the milling on both faces and the manual tilting of the workpiece (two sides, manual flip), to then assemble the whole with polyurethane glue and sili- cone. The last phase of smoothing and plastering has uniformed the surfaces for the final coating treatment (Fig. 7).

As anticipated, for the work on the findings emerged from the sea of the Egadi Islands were also adopted the techniques of virtual museum display for data sharing. The latest standards for the production of internet platforms provide that they can accommodate, in addition to traditional contents such as text, images and videos, even 3D models and augmented reality applications. The recent scientific literature on the subject proves that this is a cutting-edge aspect of the research and a technological challenge related to the HTML programming language, codes and algorithms born and developed for other functions.

Web-service, such as for example Sketchfab or Verold, allow by means of external links, to publish virtual models, but on the condition to opt for low resolutions and introduce strong simplifications in the models.

The dynamic display of textured meshes through new players, such as 3DHOP (3D Heritage Online Presenter), an open-source software package for the creation of interactive Web presentations of high-resolution 3D models, oriented to the Cultural Heritage field, created by the Visual Computing Lab of CNR-ISTI, overcomes these limitations. Specifically, 3DHOP allows the creation of interactive visualization of 3D models directly inside a standard web page, just by adding some HTML and JavaScript components in the HTML code.

The $3 \mathrm{D}$ scene and the user interaction can be easily configured 

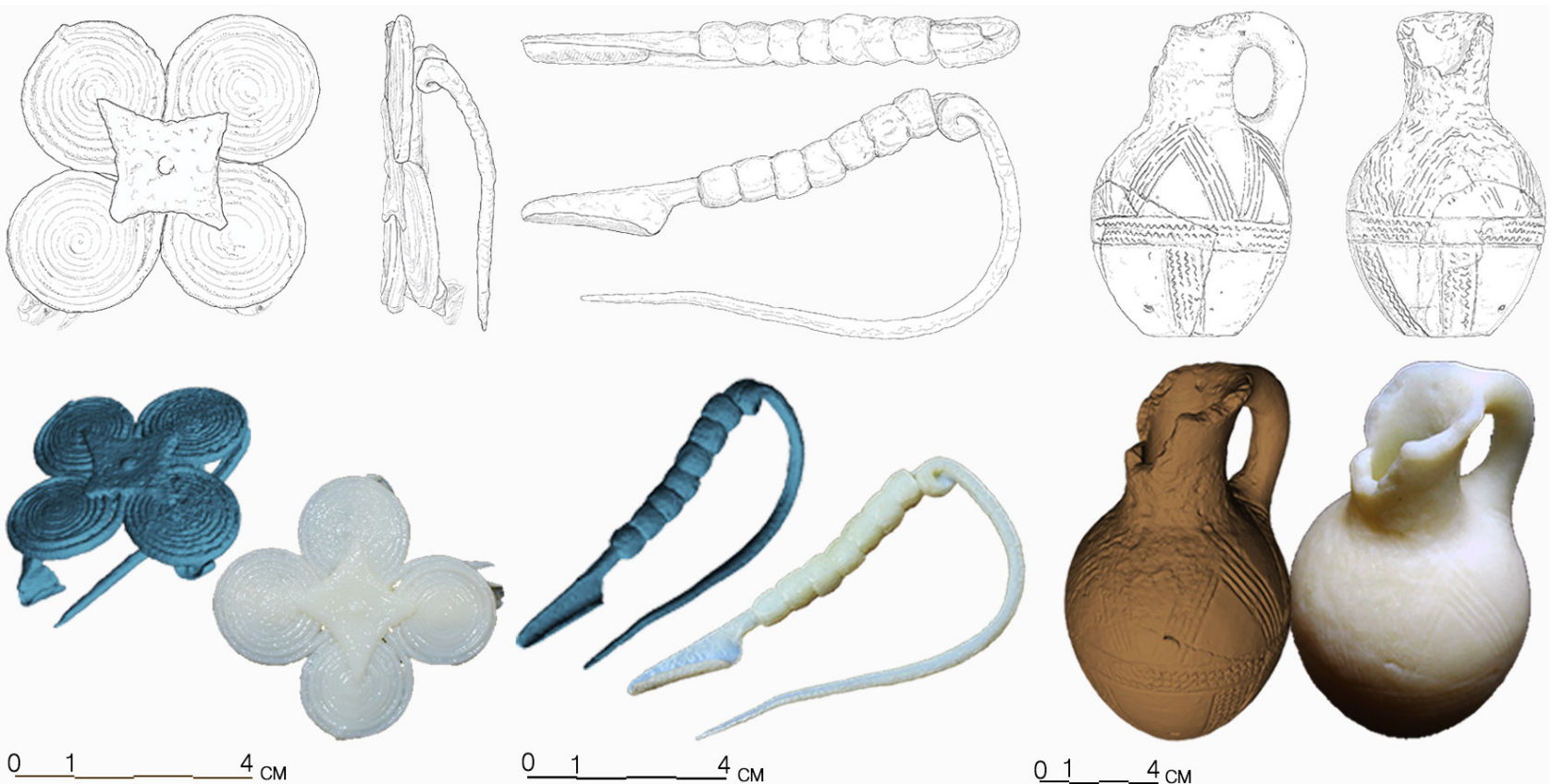

$0 \quad 1 \quad 4 \mathrm{CM}$

$\underline{0}$

$4 \mathrm{CM}$

$\underline{0.1-4} \mathrm{~cm}$

Figure 6. The archaeological artefacts belonging to the grave goods: 3D survey of the individual pieces, virtual models and prototypes.

using a simple 'declarative programming' approach, and by a series of provided JavaScript functions.

By using a multi-resolution 3D model management, supporting an efficient streaming, 3DHOP is able to work with high-resolution 3D models with ease. It is therefore permissible to conform the interface to fit any specific communication demand and then customize the graphic scene, define the number of artefacts on display, choose the lighting conditions (rendering), the way to interact for possible automatic animations (Fig. 8).

\section{CONCLUSIONS}

The work processes here shown - with the help of a series of results of activities carried out on an experimental basis and in addition to those of knowledge, understanding and analysis conducted in accordance with traditional practice - highlight how the use of new digital technologies applied to our cultural heritage, can be very useful for its safeguarding, representation, and promotion. The concept of digital heritage, recently born to define

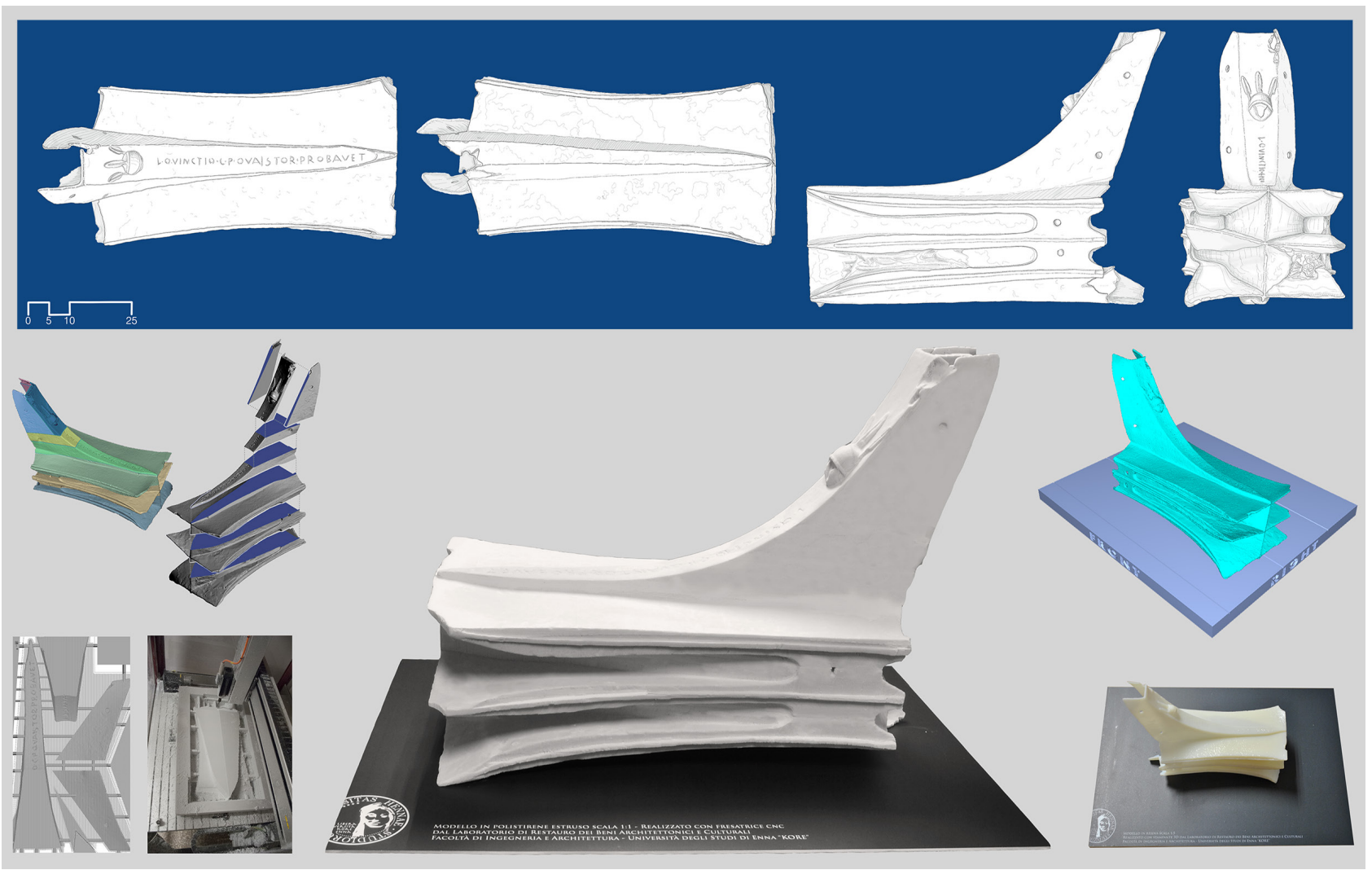

Figure 7. Maquette of the rostrum realised in scale 1: 1 by CNC machine. 

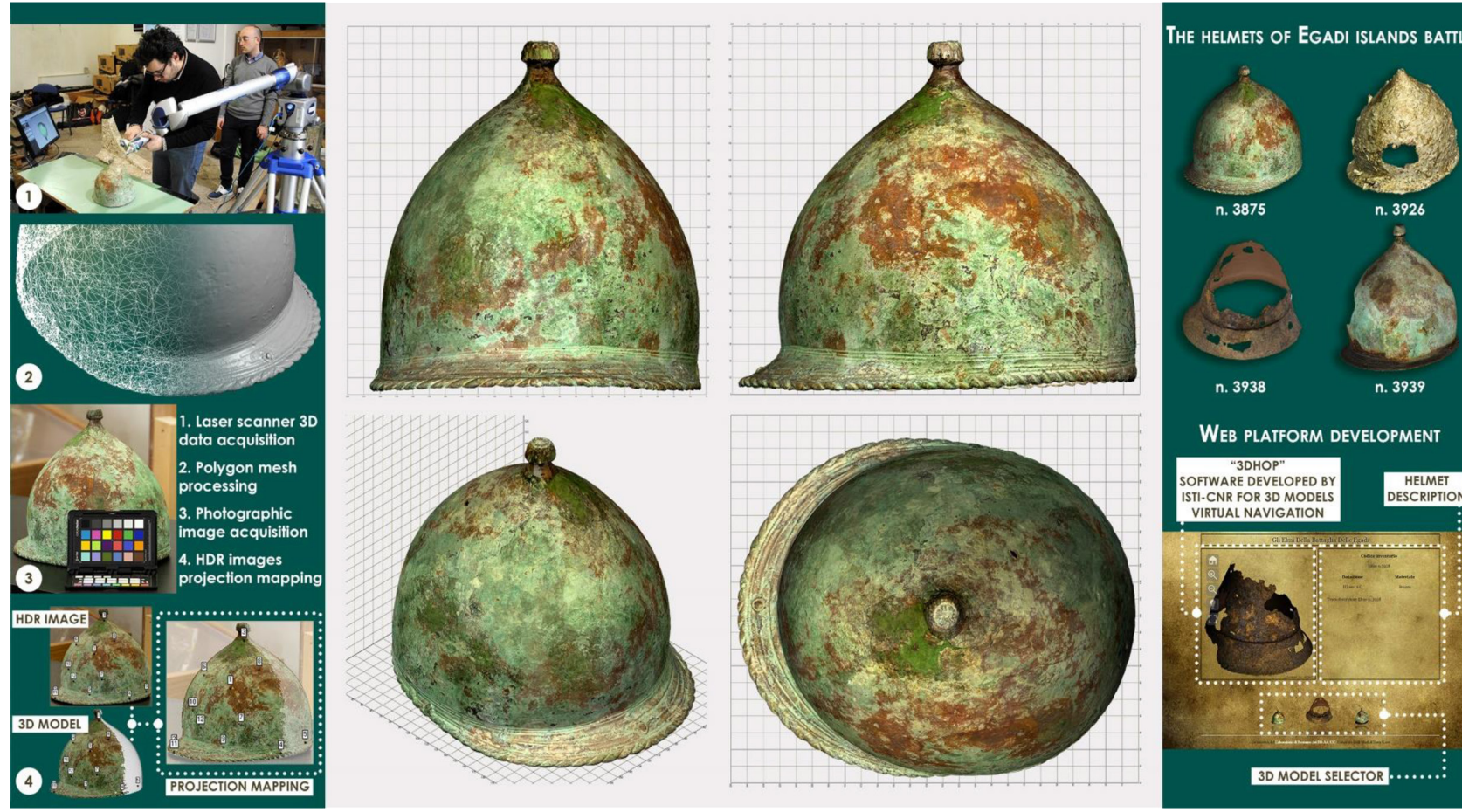

WEB PLATFORM DEVELOPMENT

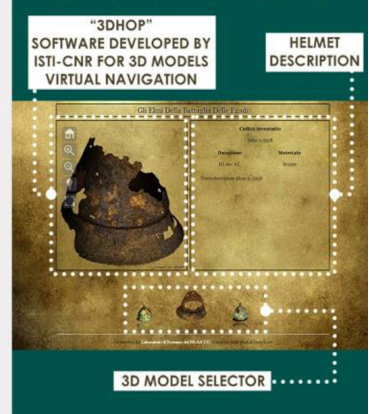

Figure 8. Generation process and 3DHOP platform for the online presentation of the high-resolution 3D models.

the use of digital media in the service of preserving cultural heritage, has transformed the process of understanding and enjoyment of our past and it is likely to become more important and more widespread over time. Current practices in the field inevitably are the result of the integration of traditional skills - history, archaeology, restoration, museology, economy, etc. - with the new tools provided by the information and communications technology. This synergy has already shown its great potential for improving many important features of the research, management, and public involvement in the protection of ancient remains but its effectiveness can be improved to capture not only the tangible aspects of heritage but also all the other aspects - even intangible - that compose its real essence. For this reason the study and optimization of these procedures are to be encouraged.

\section{ACKNOWLEDGEMENTS}

In memory of Sebastiano Tusa, tragically disappeared, to remember his commitment as an archaeologist, passionate and tireless, who has given so much to the research and promotion of Sicilian cultural heritage. Activities were carried out in the framework of research agreements between the University of Enna "Kore", Faculty of Engineering and Architecture, Laboratory of Diagnostics and Restoration of Architectural and Cultural Heritage and the Soprintendenza del Mare, the Soprintendenza BB.CC. AA. di Enna and the Centro Regionale per la Progettazione e il Restauro - Regione Siciliana. Authors would also thank the director of the Museo Regionale Interdisciplinare di Enna.

\section{REFERENCES}

Bernabò Brea, L., 1882, Calascibetta (Enna): la necropoli di Cozzo S. Giuseppe in contrada Realmese. In: Notizie degli scavi di antichità, Vol. 36, pp. 425-632.

Cardaci A., Versaci A., 2018. Rilievo e restauro, un binomio im- prescindibile: approcci metodologici e applicazioni operative finalizzate alla conoscenza e alla conservazione del patrimonio culturale. Aracne, Roma, Italy.

Guidi, G., Russo, M., Angheleddu, D., 2014. 3D survey and virtual reconstruction of archeological sites. In: Digital Applications in Archaeology and Cultural Heritage, Vol. 1 (2), pp. 55-69.

Marconi, C., 2008. Gli acroliti da Morgantina: prospettiva. In: Rivista di Storia dell'arte antica e moderna, Vol. 130-131, pp. 2-21.

El-Hakim S.F., Remondino F., Gonzo L., and Voltolini F., 2008. Effective high resolution 3D geometric reconstruction of heritage and archaeological sites from images. Layers of Perception. In: Posluschny, A., K. Lambers and I. Herzog (eds.), Layers of Perception. Proceedings of the 35th International Conference on Computer Applications and Quantitative Methods in Archaeology (CAA), Berlin, Germany, April 2-6, 2007 (Kolloquien zur Vor- und Frühgeschichte, Vol. 10, pp. 43-50.

Luigini, A., Brusaporci, S., Vattano, S., and Tata, A., 2019, 3D digital models for a widespread museum: the Renon's "Bauernhöfe". In: The International Archives of the Photogrammetry, Remote Sensing and Spatial Information Sciences, Vol. XLII-2/ W9, pp. 447-453 https://doi.org/10.5194/isprs-archives-XLII2-W9-447-2019.

Yehuda E., Kalay T. K., Affleck, J. (eds.), 2007. New Heritage: New Media and Cultural Heritage. Routledge, New York, USA.

Russo, M., Remondino, F., Guidi, G., 2011. Principali tecniche e strumenti per il rilievo tridimensionale in ambito archeologico, In: Archeologia e Calcolatori, Vol. 22, pp. 169-198.

Sanz, F. Q., 2007. Montefortino-type and related helmets in the Iberian Peninsula: a study in archeological context. In: Journal of roman military equipment studies, Vol. 8, pp. 151-166. 